\title{
Obesity: considerations about etiology, metabolism, and the use of experimental models
}

This article was published in the following Dove Press journal:

Diabetes, Metabolic Syndrome and Obesity:Targets and Therapy 5 April 2012

Number of times this article has been viewed

\section{Luciana O Pereira-Lancha \\ Patricia L Campos-Ferraz Antonio $\mathrm{H}$ Lancha Junior \\ School of Physical Education and Sport, University of Sao Paulo, Sao Paulo, Brazil}

\begin{abstract}
Studies have been conducted in order to identify the main factors that contribute to the development of obesity. The role of genetics has also been extensively studied. However, the substantial augmentation of obesity prevalence in the last 20 years cannot be justified only by genetic alterations that, theoretically, would have occurred in such a short time. Thus, the difference in obesity prevalence in various population groups is also related to environmental factors, especially diet and the reduction of physical activity. These aspects, interacting or not with genetic factors, could explain the excess of body fat in large proportions worldwide. This article will focus on positive energy balance, high-fat diet, alteration in appetite control hormones, insulin resistance, amino acids metabolism, and the limitation of the experimental models to address this complex issue.
\end{abstract}

Keywords: obesity, diet, leptin, fat, ghrelin, experimental models

\section{Introduction}

Evidence suggests that overweight and obesity prevalence have been arising at alarming rates, both in developing and developed countries. Nearly two-thirds of the adult American population, for example, is already overweight or obese. ${ }^{1}$

Obesity is considered pandemic, as described by the World Health Organization. ${ }^{2,3}$ In Brazil, the demographic, economical, and epidemiological changes that took place (intense urbanization process, increased penetration of "western culture," and globalization, resulting in unfavorable diet and physical activity habits, especially among the poor) in recent years have led to a transition in nutritional patterns: reduction of malnutrition and augmentation of obesity cases. ${ }^{4-7}$

The first, second, and third National Health and Nutrition Examination Surveys (NHANES), ${ }^{8}$ conducted in the United States during the years 1971-1974, 1976-1980, and 1988-1991, respectively, showed that in spite of the USD33 million spent by the "weight loss" industry, the number of obesity cases has been rising significantly, with no differences in race and social status. In NHANES II, $25.4 \%$ of the adults were considered to be beyond ideal weight (body mass index $>27.5 \mathrm{~kg} / \mathrm{m}^{2}$ ); in NHANES III this percentage reached $33.3 \% ;^{8}$ in NHANES $1999-2000$, this percentage was more than $64 \%$, which was maintained during another study conducted between 2001-2002. ${ }^{9}$

The consequences of obesity to one's health are many and range from a higher risk of premature death to severe nonlethal disease (comorbidities) associated to it. Obesity is frequently related to hyperlipidemia ${ }^{10-12}$ and to type 2 diabetes, ${ }^{12}$ two conditions intimately related to cardiovascular diseases. ${ }^{13-15}$
Cidade Universitaria,

Sao Paulo 05508-90I, Brazil

$\mathrm{Tel}+55$ I | 309| 3096

Fax +55 II 309। 38I9

Email lanchajr@hotmail.com 
Ever since complications of obesity to health have been demonstrated, many studies have been conducted in order to identify the main factors that contribute to its development. The role of genetics in the etiology of obesity has also been extensively analyzed. The identification and sequence of the ob gene, which encodes the peptide leptin, and the finding that a simple impairment in this gene seems to be the main cause of obesity in ob/ob rats ${ }^{16}$ have raised the interest in obesity genetics. However, the substantial augmentation of obesity prevalence in the last 20 years cannot be justified by genetic alterations that, theoretically, would have occurred in such a short time. ${ }^{17,18}$ Thus, some authors emphasize that the difference in obesity prevalence in various population groups is related to environmental factors, ${ }^{18,19}$ especially diet ${ }^{2,19-21}$ and the reduction of physical activity. $2,3,19,20,22-24$ The aim of this review is to correlate these aspects both in humans and in experimental models, whether or not interacting with genetic factors, in order to try to explain the excess of body fat in large proportions worldwide. ${ }^{25,26}$

\section{Obesity-inducing factors Energy balance}

Positive energy balance is an important etiology factor to obesity development, by promoting augmentation in energy storage and body weight. ${ }^{27,28}$ Results obtained by the authors' group demonstrated a high sedentary rate in obese subjects. In this study, $80 \%$ of the participants did not do any physical activity. ${ }^{29}$ In addition, modernization and the economic transition featured in most countries have enhanced processed food intake, which leads to high protein and hyperlipidic diets, and a reduction of complex carbohydrate content. ${ }^{30}$ This dietary pattern also seems to be repeating in countries such as Brazil. Studies conducted by the authors' group with obese Brazilian women showed that more than $30 \%$ of total caloric intake of this group had been provided by lipids, ${ }^{31-35}$ which characterizes a dietary pattern similar to that featured in developed western countries.

In line with this, sedentary life and nutritional habits seem to represent the main risk factors for the etiology of pandemic obesity., ${ }^{2,627}$ It seems to be the same in Brazil: in 1997 , obesity prevalence was estimated to be $11 \%,{ }^{36}$ while it was around $9.6 \%$ in 1989 , and $5.7 \%$ in $1974 .{ }^{5}$ In 1975 , there were almost two cases of malnutrition to one of obesity; in 1997 this situation was the exact opposite. Different from other countries, with increasing obesity rates in all social levels, low income for the Brazilian population makes it more susceptible to obesity. ${ }^{37}$
Monteiro et al ${ }^{38}$ evaluated the evolution of obesity in Brazil by using data of three national surveys: National Survey of Household Expenditure (ENDEF) 1974, National Health and Nutrition Survey (PNSN) 1989, and the Consumer Expenditure Survey (POF) 2002-2003. In the first 14-year period (1975-1989), obesity rates between men and women increased $92 \%$ and $63 \%$, respectively, and the highest rates were found among the low income population. In the second 14-year period (1989-2003), there was an obesity increase even higher in men and a stabilization of this condition in women in general; however among the low income women, there was a $26 \%$ increase in obesity. Thus, Monteiro et al highlighted that the distribution of obesity prevalence among the different social classes is especially important.

\section{Obesity, hyperlipidic diet and appetite- regulating hormones}

The literature indicates that not only energy intake and energy expenditure regulate energy body storage. The balance of each nutrient seems to be rigorously controlled to adjust its intake to its oxidation (and vice versa), as recently reviewed by Pereira-Lancha et al. ${ }^{39}$

High-fat diets may lead to hyperphagia or cause metabolic effects regardless of this condition, ${ }^{40}$ such as lipolytic activity reduction in fat tissue, ${ }^{41}$ reduction in leptin secretion, ${ }^{42}$ and/or limitation of leptin capacity. ${ }^{43}$ Some studies indicate that impairment on mitochondrial metabolism may lead to excessive body weight gain when the subjects are fed with high-calorie western diets. ${ }^{44}$ The study of Townsend et a ${ }^{45}$ offered two different diets (hyperlipidic and hypolipidic) to rats, both diets predominant in saturated fat. The animals which consumed a high-fat diet, despite featuring lower total energy intake, had increased body fat more than the low-fat diet group, and had a higher weight gain even with increased leptin levels, pointing to the mechanism of leptin resistance. Townsend et al highlighted that the augmentation of caloric ingestion is not fundamental to stimulating adiposity increase by hyperlipidic diet in rats. Obese individuals feature elevated plasma leptin levels, indicating leptin resistance, which may be caused by impairment in the leptin binding protein that takes leptin to the brain, impairment in the expression and/or signaling of the brain leptin receptor, and impairment in the leptin synthesis/secretion by adipocytes. ${ }^{46}$

Other than leptin, signals provided by the gastrointestinal tract also have an important role in appetite regulation and energy intake (Figure 1); among them are cholecystokinin (CCK), glucagon-like peptide 1, pancreatic polypeptide, 


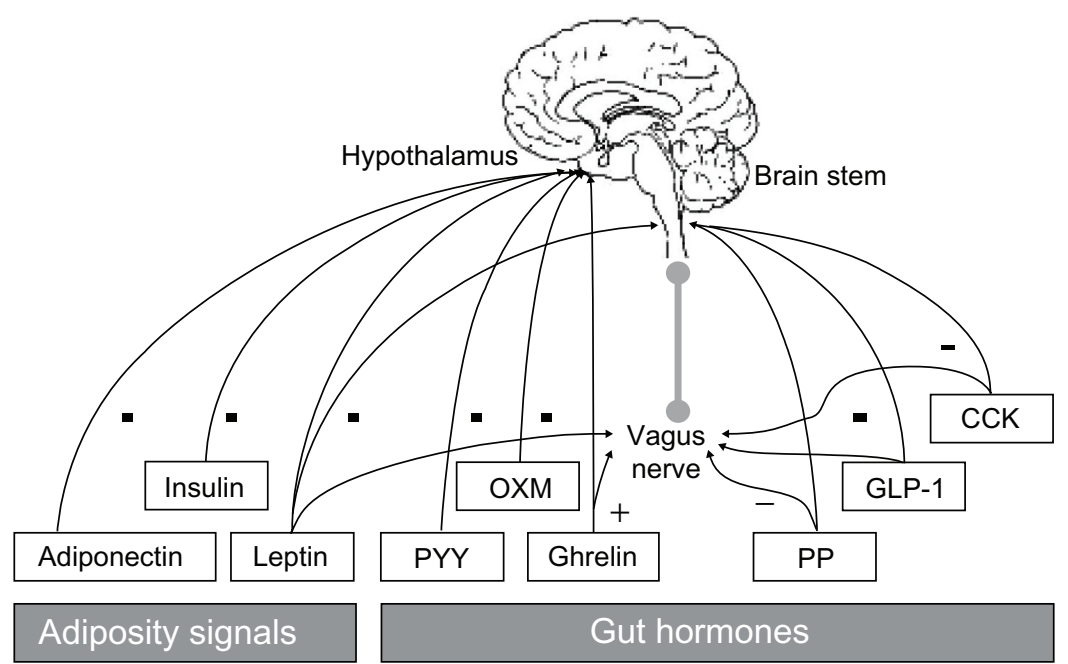

Figure I Evidence suggests that the mechanisms inhibiting both appetite and caloric ingestion may be impaired in obese individuals. ${ }^{48}$

Note: This is not yet consensual in the literature, although many authors have been trying to clarify how the mechanisms regulating hunger and satiety behave in this population. Reproduced with the permission of The American Physiological Society from Little TJ, Horowitz M, Feinle-Bisset C. Modulation by high-fat diets of gastrointestinal function and hormones associated with the regulation of energy intake: implications for the pathophysiology of obesity. Am J Clin Nutr. 2007;86(3):53I-54I.

Abbreviations: CCK, cholecystokinin; GLP-I, glucagon-like peptide I; OXM, oxyntomodulin; PP, pancreatic polypeptide; PYY, peptide YY.

all of which have a negative effect on energy balance, and ghrelin, which has the opposite effect. ${ }^{47}$

Evidence suggests that the mechanisms inhibiting both appetite and caloric ingestion may be impaired in obese individuals. ${ }^{48}$ This is not yet consensual in the literature, although many authors have been trying to clarify how the mechanisms regulating hunger and satiety behave in the obese population.

\section{CCK}

CCK is one of the most studied hormones regarding food intake regulation. It is largely found in the central nervous system and produced by the jejunum and duodenum as food enters the intestine, especially protein and fat-rich foods, which can increase CCK levels up to five times. When administered, CCK can induce satiety and reduce food portion sizes both in humans and other species in a dosedependent manner.

The mechanisms by which CCK exerts these effects are controversial. One of the hypotheses is that CCK inhibits gastric peristalsis, mainly by gastric emptying. CCK may also act on vagal afferent nerve fibers to induce cardiovascular effects and reflex inhibition of splanchnic sympathetic nerve discharge ${ }^{49}$ It has been well described that adult rats chronically fed a high-fat diet maintain reduced sensitivity to CCK. Swartz et al ${ }^{50}$ demonstrated that male rat pups fed a high-fat diet exhibit reduced sensitivity to CCK; the development of this reduced sensitivity is quicker than its extinction when the high-fat diet was switched to a low-fat diet.

\section{Peptide YY (PYY)}

PYY is secreted by intestine cells after food intake, exerting a negative feedback (inhibits food consumption); however, it has been demonstrated that in obese individuals, PYY levels are lower than in normal people, making this mechanism of satiety less efficient in this case. ${ }^{51}$

Plasma levels of PYY are reduced during a fasted state; they increase gradually approximately 15 minutes after meal initiation. PYY release peak levels occur 1-2 hours after the meal begins and are elevated until 6 hours later. PYY levels are dependent on meal macronutrients and calories, and a proteinrich meal seems to increase PYY levels more than fat-rich or carbohydrate-rich isocaloric meals. In addition, the more protein that is in a diet, the higher the PYY levels..$^{52}$ Besides nutrients and calories, bile, hydrochloric acid, vasoactive intestinal polypeptide, and CCK also enhance PYY release. ${ }^{53}$ Studies with PYY administration in humans and animals featured both appetite and food intake reduction up to $30 \%$ for up to 24 hours. This therapeutic effect might be especially useful in the treatment of obesity, since obese individuals present reduced PYY levels. ${ }^{54}$ More and more evidence has demonstrated that PYY has considerable effect on energy expenditure and substrate utilization. Some studies have shown that PYY chronic administration alters substrate utilization favoring fat oxidation. ${ }^{55}$ Moreover, overexpressing PYY animals feature higher basal temperature, indicating increased thermogenesis. ${ }^{56} \mathrm{~A}$ study performed with humans comparing eutrophic and obese individuals showed that PYY peripheral infusion increased energy expenditure and fat oxidation. ${ }^{57}$ 
These data might indicate that the use of this peptide in obesity treatment can be very promising.

\section{Ghrelin}

On the other hand, ghrelin is synthesized and secreted both in the stomach and the intestine, stimulating food intake. Its normal levels are usually low after meals; however, in obese subjects, ghrelin levels are elevated after food intake, stimulating hunger. ${ }^{58}$ In fact, some studies evidenced that obese subjects submitted to weight loss treatment demonstrate increased ghrelin levels. ${ }^{59}$

Ghrelin reaches it maximal plasma levels before meals in order to stimulate food intake. After the meal, its levels are reduced to its lowest point approximately 60-90 minutes later, returning to basal parameters. A new release peak occurs a few moments before a new meal. ${ }^{60}$ Kinetics of ghrelin plasma concentrations suggest that it is the signal for hunger initiation. Chronic ghrelin administration in rodents results in hyperphagia and body weight gain regardless of ghrelin-induced growth hormone level increases.

Exercise also regulates ghrelin secretion. A study showing the effects of time and intensity of exercise on this parameter showed that subjects who cycled for 120 minutes/day consumed significantly more food compared to those who trained 30 or 60 minutes/day and to the control group. ${ }^{61}$

One of the reasons why diet fat may lead to hyperphagia also comes from its organoleptical properties, ${ }^{62}$ such as high palatability, characteristic texture, ${ }^{21,63}$ and large utility and versatility as a culinary ingredient. ${ }^{64} \mathrm{~A}$ high-fat diet is preferably consumed even by rats when they can choose among three different chemically defined diets, each of them rich in one of the three primary macronutrients. ${ }^{65}$

However, a few authors believe that the type of diet fat can also influence body fat storage, since there are studies showing significant correlation between body fat percentage and saturated and monounsaturated diet fat percentage ${ }^{66}$ Rats submitted to a high-fat diet for 7 weeks (58\% total caloric intake), rich in saturated fat, developed greater adiposity when compared to animals fed with diets rich in omega 3 and omega 6 fats and control animals fed with an isocaloric lowfat diet. ${ }^{67}$ Matsuo and Suzuki ${ }^{68}$ demonstrated altered affinities of $\beta$-adrenergic receptors in brown adipose tissue, the heart, and soleus muscle as a consequence of a high-fat diet rich in saturated fatty acids. Awad and Zepp ${ }^{69}$ demonstrated that rats fed with a saturated fatty acid-rich diet featured lower lipolysis rates than animals fed with a polyunsaturated fatty acid-rich diet, due to a lower activity of hormone sensitive lipase. Others have also indicated that saturated fatty acid intake enhances body fat storage accumulation by a reduction of sympathetic activity in brown adipose tissue, the heart, and skeletal muscle. . $8,70^{-}$

The activity of carnitine-palmitoyltransferase complex (CPT-1) and, consequently, $\beta$-oxidation in brown adipose tissue have also been reported to reduce with the intake of saturated fatty acids. ${ }^{71}$ In fact, mitochondrial membrane fluidity, which is determined by a cholesterol/phospholipids rate and by the instauration of the fatty acids that constitute membrane phospholipids, seems to be directly related to CPT-1 activity in the liver. ${ }^{72}$

\section{Obesity and insulin resistance}

Obesity is responsible for triggering a group of metabolic disorders with vascular implications named metabolic syndrome,${ }^{73}$ which is characterized by hyperinsulinemia, high levels of glycemia or diabetes, and at least two different levels of insulin resistance that explain the relationship between various abnormalities and this disease. ${ }^{74}$

Insulin resistance is defined by reduction of its capacity to stimulate glucose utilization, ${ }^{75}$ either by insulin deficiency or by impairment in its secretion and/or utilization. ${ }^{76}$ There is also an intermediate situation between glucose homeostasis and diabetes named glucose intolerance or reduced glucose tolerance. $^{76}$

Lipid accumulation in the liver is considered to be one of the primary mechanisms relating obesity-related insulin resistance and type 2 diabetes. Glucose uptake is reduced by insulin resistance in muscle and fat cells, whereas insulin resistance in liver cells results in both reduced glycogen synthesis and storage and a failure to suppress glucose production and release into the blood. ${ }^{77}$ Abdominal adiposity correlates with hepatic glucose production, and it is also known that free fatty acid flux is increased in obese subjects with upper body adiposity. When free fatty acids are elevated, insulin's ability to suppress hepatic glucose production is markedly attenuated, and this effect is most evident in subjects with impaired glucose tolerance and type 2 diabetes. ${ }^{77}$

Although obesity is pointed at as the most common cause of insulin resistance, not all obese individuals develop this alteration. According to various authors, ${ }^{78-80}$ what determines the occurrence of metabolic dysfunction is the location of the accumulation of body fat - mainly visceral adiposity, ${ }^{80}$ gender, ${ }^{81}$ and low physical activity levels. ${ }^{82}$

It is well established that exercise improves insulin sensitivity. Laaksonen et $\mathrm{al}^{83}$ studied 612 men who were followed for 4 years. Of these, 107 subjects developed metabolic syndrome, $40 \%$ of them exercised less than 
3 hours/week. Other than that, these subjects featured higher blood pressure levels, were heavier, and more dyslipidemic and hyperinsulinemic than the subjects who did not have metabolic syndrome. Laaksonen et al concluded that exercise above the American College of Sports Medicine recommendations strongly reduced the risk of developing metabolic syndrome.

Many studies indicate an augmentation in lipid oxidation when caloric expenditure is higher in obese patients with high-fat intake and elevated rate of lipolysis, which is directly related to body fat storage. ${ }^{84}$ This preferential free fatty acid utilization from triacylglycerol storage as an energy substrate would be responsible for reducing glucose mobilization via glycogen. This would lead to a negative feedback of muscle and liver glycogen upon glycogen synthase activity and, consequently, on glycogen storage. Recently, Lancha Jr et al ${ }^{85}$ demonstrated the inverse relationship between glycogen content and glucose uptake, ie, the fed animals featured higher glycogen storage and lower glucose uptake whereas the fasted animals had the opposite situation. However, currently, the mechanisms related to glycogen and glucose transport are uncertain; although, some authors believe that glycogen could regulate glucose transport by agglutination of glucose transporter type 4 (GLUT4) molecules and further incorporation into glycogen complex and enzymes. This results in insulin resistance and glucose intolerance; diabetes appears in obese patients after a long period of glucose intolerance and when glycemia does not return to the basal state, there is insulin resistance, ${ }^{86}$ which leads to hyperinsulinemia. ${ }^{87-89}$
In rats fed with a high-fat diet, the development of obesity has been observed, ${ }^{90-93}$ as previously stated, as well as a reduction in systemic, muscle, and adipocyte insulin action..$^{90-95}$ Raubenheimer et $\mathrm{al}^{96}$ fed rats with a $45 \%$ fat diet for 8 weeks and observed an increase in body weight, triacylglycerol levels of $117 \%$, hyperinsulinemia, and glucose intolerance. Nascimento et $\mathrm{al}^{97}$ demonstrated that animals fed with hyperlipidic diets featured lower phosphorylation of one of the proteins of the insulin signaling mechanisms (protein kinase B/Akt), a denotation of reduced insulin action, and resistance induced by diet.

High-fat diet intake has been given much attention, especially in regards to its effects on insulin action alteration. These alterations have already been observed in a very short period of time, for example, 7 days,${ }^{92} 10$ days, ${ }^{91} 3$ weeks, ${ }^{98}$ and 4 weeks. ${ }^{95}$ Various studies demonstrated that insulin resistance occurs primarily in the liver, in a very short time (3 days), followed by insulin action impairment in some groups of skeletal muscles. ${ }^{99,100}$ These effects depend on the type of diet fat (amount, size, and number of unsaturations). ${ }^{101}$ The prolonged exposition of adipocytes to saturated fatty acids has caused insulin resistance in these cells. ${ }^{102}$ Many mechanisms have been proposed to explain the action of lipids in gene expression control of both GLUT4 and insulin receptors. Tebbey et al $^{103}$ suggested that arachidonic acid $(n=6)$ reduces the stability of GLUT4 messenger ribonucleic acid, lowering their levels rapidly.

According to Duplus et al, ${ }^{104}$ fatty acid molecules may act in various moments of gene transcription. Figure 2 shows some possible mechanisms to illustrate this. For example,

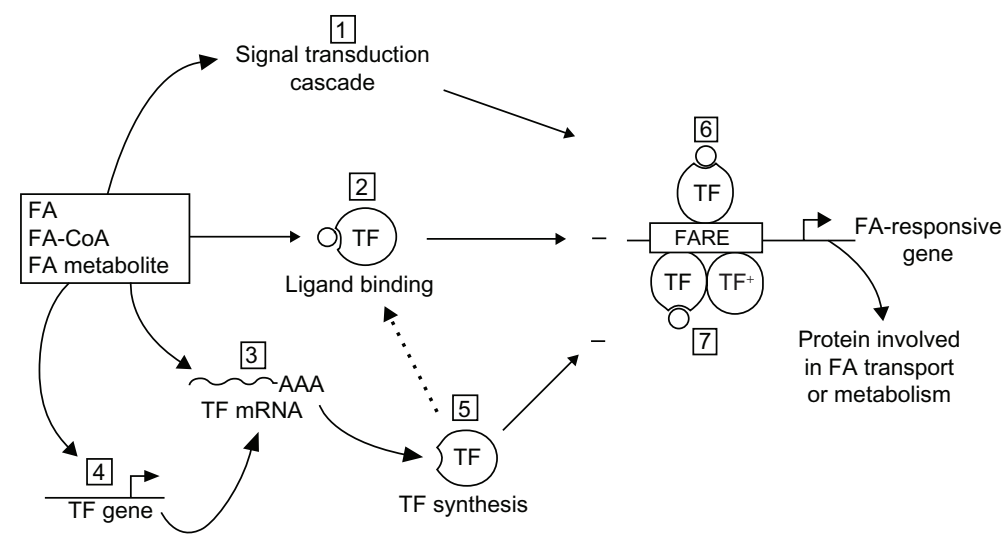

Figure 2 Postulated mechanisms for fatty acid control of gene transcription. ${ }^{104}$ The FA per se, FA-CoA, or FA metabolite modulate ( \pm ) transcription of a responsive gene, encoding a protein involved in FA transport or metabolism, through various non-mutually selective potential mechanisms. Step I: a signal transduction cascade is initiated to induce a covalent modification of a TF, thereby modifying its transcriptional potency. Step 2: the FA itself or its derivative acts as a ligand for a TF, which then can bind DNA at a FA response element and activate or repress transcription. Steps 3, 4 and 5: FA can act indirectly via alteration in either TF mRNA stability (Step 3) or gene transcription (Step 4), resulting in variations of de novo TF synthesis (Step 5) with an impact on the transcription rate of genes encoding proteins involved in FA transport or metabolism. On binding to the eognate response element, TF acts either as a monomer (Step 6), a homodimer, or a heterodimer with TF+, a different TF (Step 7).

Notes: Reproduced with the permission of the American Society for Biochemistry and Molecular Biology from Duplus E, Glorian M, Forest C. Fatty acid regulation of gene transcription. J Biol Chem. 2000;275(40):30749-30752. Copyright (C) 2000, by the American Society for Biochemistry and Molecular Biology.

Abbreviations: FA, fatty acids; FA-CoA, fatty acyl-CoA; TF, transcription factor. 
fatty acids could initialize a signaling cascade, in a covalent way, to modulate the transcription factor. Another possibility would be the liaison of fatty acid to the transcription factor to activate or inhibit this process. Finally, fatty acids could modify messenger ribonucleic acid stability, as stated before, and also alter de novo synthesis of the transcription factor, altering protein synthesis.

Another hypothesis to explain gene expression modulation by hyperlipidic diets is related to nuclear receptors like peroxisome proliferator-activated receptors (PPARs), which act like transcription factors. It has been demonstrated that PPARs aid glucose uptake regulation via adiponectin, a protein expressed mainly by white adipose tissue. Their levels are reduced in various types of obesity and insulin resistance. ${ }^{79}$ High-fat diet intake also seems to exert effects upon gene expression of PPAR $\gamma$ coactivator $1 \alpha$. PPAR $\gamma$ coactivator $1 \alpha$ consists of a PPAR coactivator, and both have a strict relationship with adipocyte synthesis and apoptosis and with increased insulin sensitivity. Sparks et al's study ${ }^{105}$ demonstrated that after 3 days of diet, animals featured a reduction in PPAR $\gamma$ coactivator $1 \alpha$ gene expression of approximately $25 \%$.

Mammalian target cells of rapamycin are possibly enrolled in the mechanisms of insulin resistance, as indicated by various in vitro studies, through its signaling pathway. ${ }^{106}$ Nevertheless, whether this interference is significant or not in vivo is still a controversial point. Reynolds et a ${ }^{107}$ recently demonstrated that a hyperlipidic diet rich in saturated fat caused insulin resistance in rats. However, this situation was not reversed in the presence of rapamycin, a powerful and specific mammalian target of rapamycin inhibitor. Thus, Reynolds et al concluded that the progression of insulin resistance in rats, resulting from a high-fat intake, was not dependent on mammalian target of rapamycin activation in skeletal muscle.

Adipose tissue is an important source of proinflammatory cytokines and adipokines. It is known that subclinical inflammation in obese individuals may be a consequence of elevated cytokine secretion by adipocytes, contributing to the development of metabolic syndrome. ${ }^{80}$ Adipokines and cytokines secreted by white adipose tissue include leptin (appetite inhibitor and $\mathrm{T}$ cell proliferation modulator); adiponectin (potent vascular protector associated to adequate glucose uptake, with concentration inversely proportional to adiposity), ${ }^{79}$ resistin (gives resistance to insulin); and tumor necrosis factor $\alpha$ (TNF- $\alpha$; reduces adiponectin production). ${ }^{108}$ According to some authors, TNF- $\alpha$, a transmembrane protein, could also explain alterations in gene expression of molecules evolved in glucose uptake, mediated or not by insulin, after a high-fat diet intake. TNF- $\alpha$ may act on the insulin signaling cascade, phosphorilizing insulin receptor substrate 1 serine residues, which impairs its binding capacity to the insulin receptor and inhibits signal propagation. ${ }^{109}$

In addition to its effect on the insulin signaling cascade, some studies indicated that TNF- $\alpha$ is capable of reducing GLUT4 gene expression. ${ }^{110}$ Jove et al ${ }^{111}$ studied the effect in vitro of saturated fat on TNF- $\alpha$ gene expression and verified that there was an augmentation of 2.5 times in both gene and protein expression, which was inversely correlated to GLUT4 levels and glucose uptake. Borst et al ${ }^{112}$ administered an antiTNF- $\alpha$ substance to Sprague Dawley rats and verified an increase of more than $60 \%$ in muscle glucose transport. The high-fat diet utilized in this study has already been associated to a TNF- $\alpha$ level increase in Wistar rats. ${ }^{113}$ Thus, it is possible that TNF- $\alpha$ might have contributed, at least in part, to the modification of glucose tolerance in this study. However many of these hypotheses are not demonstrated yet and more studies are necessary to completely understand the alterations in gene expression of various proteins after high-fat diets.

Many studies have tried to identify the causes of glucose uptake alterations due to high-fat diets; nevertheless this issue is still controversial. One of the hypotheses is that alteration of glucose receptors impair insulin action, mainly by reduction of GLUT4 activity. For example, Zierath et $\mathrm{al}^{114}$ found impairment in GLUT4 activity in muscle tissue after high-fat diet consumption in rats.

\section{Interrelations between obesity and amino acid metabolism}

Some authors believe that amino acids could have important implications in insulin postreceptor mechanisms, impairing GLUT4 vesicle translocations. ${ }^{115}$ Lancha $\mathrm{Jr}^{116,117}$ found reduced glucose transport in skeletal muscles of Wistar rats supplemented with aspartate and asparagine (both $45 \mathrm{mg} / \mathrm{kg}$ body weight/day) for 5 weeks when compared to the control group. Tyrosine kinase is an enzyme responsible for structural modifications of insulin receptor substrate 1 during the events of the first cell cycle. No alteration in tyrosine kinase activity has been found in supplemented rats; ${ }^{116,118}$ amino acids may have interfered in any of the numerous postreceptor episodes.

An elevated fat intake and low carbohydrate consumption found in obese patients may be responsible for elevating free fatty acid plasma levels and, consequently, increasing body fat storage in adipose tissue. ${ }^{119}$ Hyperlipidic diets promote 
an increase of CPT-1 activity in liver and muscle tissue, augmenting lipid oxidation. ${ }^{120}$ According to Liu et al, ${ }^{121}$ one of the factors that increases muscle CPT-1 activity, due to high-fat diets rich in unsaturated fatty acids, is the reduction of CPT-1 sensitivity to malonyl-coenzyme A (CoA). Synthesized from acetyl-CoA carboxylation, malonyl-CoA is critical in the regulation of lipid metabolism, providing acetyl-activated groups to fatty acid chain synthesis and inhibiting CPT-1 and, consequently, $\beta$-oxidation. The high intake of unsaturated fatty acids would augment mitochondrial membrane fluidity, reducing CPT-1 inhibition by malonyl-CoA. ${ }^{121}$ The fatty acid flux increases towards mitochondrion and, according to Koves et al, ${ }^{122}$ is not accompanied by complete $\beta$-oxidation due to the incapacity of the tricarboxylic acid (TCA) cycle to adjust to increased oxidative demand. Thus, metabolites would accumulate in its interior, leading to mitochondrion stress and insulin resistance. Nevertheless, a study conducted by Bruce et al ${ }^{123}$ demonstrated that when an overexpression of CPT-1 in muscle tissue is produced, impaired insulin sensitivity due to a high-fat diet improved. Bruce et al had already found an increase in CPT-1 activity, insulin resistance, triacylglycerols, and fat storage in cell membranes associated with a high-fat diet. According to them, obesity as a consequence of a fatrich diet results in an increase of lipids entering the cell with a subsequent increase in oxidation. However, an increase in fat oxidation is quantitatively lower than lipids entering the cell, and results in higher fat deposits in the cell. The accumulation of these bioactive lipid molecules as ceramides and diacylglycerols might modify lipid characteristics of the cell membrane, interfering in insulin action. However, when promoting CPT-1 overexpression in muscle tissue, insulin resistance was reduced. Thus, Bruce et al suggested that fat entering the mitochondrion is more critical in regulating fatty acid oxidation than $\beta$-oxidation and the TCA cycle.

In line with this, for this process to be triggered and the TCA cycle to run normally, there has to be an oxaloacetate yield in the same proportion as acetyl-CoA. In regular conditions, glycogen is more relevant initially, and plasma glucose has a more discrete participation; afterwards, when a reduction in the storage occurs, plasma glucose assumes this function of oxaloacetate provision by glycolysis and further conversion of pyruvate to oxaloacetate. ${ }^{124}$ Nevertheless, when glucose/glycogen concentration is reduced due to fasting or low carbohydrate intake, or when resulting from insulin resistance for example, oxaloacetate yield becomes deficient. Amino acids are processed in muscle in order to correct this deficiency; leucine, isoleucine, valine, aspartate, and asparagine may be metabolized in muscle tissue to generate TCA cycle intermediates (such as succinate and oxaloacetate) to maintain its flux. These amino acids donate their carbon chains to form intermediates and release ammonia in muscle tissue. Table 1 indicates the amino acids metabolized directly by muscles, the enzymes responsible for transferring amino groups, and the intermediates formed.

As long as the TCA cycle is maintained, there will be an increase in citrate levels that will inhibit phosphofructokinase, ${ }^{124}$ reducing glucose utilization and, as a consequence, glucose uptake. This is one of the hypotheses suggested by some authors to explain the reduction in glucose uptake and, consequently, insulin resistance. Another possibility suggested by Marshall et al, ${ }^{125}$ among others, to clarify insulin resistance in this situation is the glycosylation of postinsulin substance receptors due to an increase in glucosamine levels, which is a product of the hexosamine pathway. In this case, ammonia that is liberated from muscle cells by amino acid metabolism would be shifted to $\alpha$-ketoglutarate, which is a TCA cycle intermediate, generating glutamate. Glutamate and ammonia would be metabolized by glutamine synthase, resulting in glutamine synthesis. Glutamine is usually utilized as an energy source by the intestine and immune cells. Nevertheless, a high glutamine production, as a consequence of the elevated TCA cycle activity, would stimulate the hexosamine pathway (Figure 3). In this pathway, glutamine and fructose 6-phosphate generate glucosamine 6-phosphate and other products in a reaction catalyzed by glutamine: fructose 6-phosphate amino transferase. ${ }^{126}$

The augmentation of amino acid metabolism, which generates oxaloacetate and other intermediates to the Krebs cycle, implies elevation of the cell oxidative capacity and may also provoke other cell structural alterations (Figure 4). ${ }^{127}$ Other studies also evidenced structural changes related to amino acid supplementation, and the authors justified these results as a consequence of an increase cell protein turnover ${ }^{128}$

Table I Amino acid processes in muscle metabolism and their respective enzymes, yielding tricarboxylic acid cycle intermediates

\begin{tabular}{lll}
\hline Amino acids & Enzymes & Intermediates \\
\hline Aspartate & Aspartate aminotransferase & Oxaloacetate \\
Asparagine & Asparagine aminotransferase & Oxaloacetate \\
Isoleucine & Leucine aminotransferase & Acetyl-CoA and \\
& & Propionil-CoA \\
Leucine & Leucine aminotransferase & Acetyl-CoA \\
Valine & Valine aminotransferase & Succinate \\
\hline
\end{tabular}

Abbreviation: CoA, coenzyme A. 


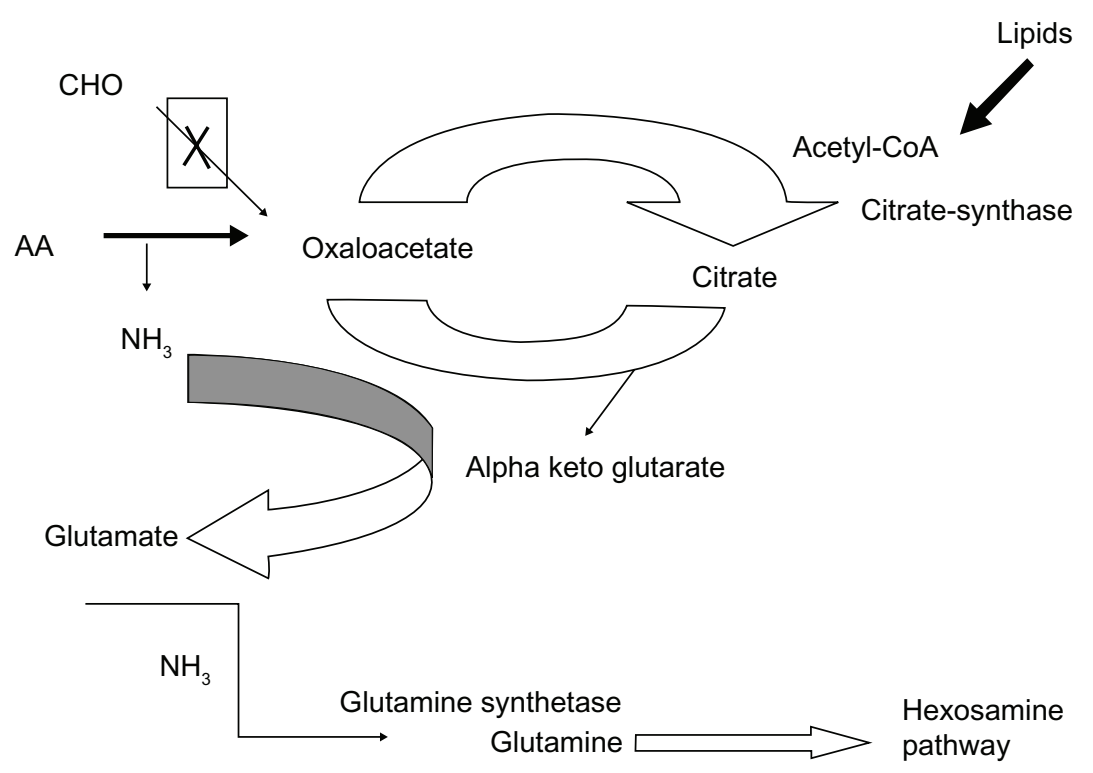

Figure 3 Adaptation of muscle metabolism to a high availability of lipids.

Note: Reduced participation of carbohydrates and high amino acid participation in anaplerotic reactions are observed, activating the hexosamine pathway.

Abbreviations: $\mathrm{AA}$, amino acid; $\mathrm{CHO}$, carbohydrate; $\mathrm{CoA}$, coenzyme $\mathrm{A} ; \mathrm{NH}_{3}$, ammonia.

or of mitochondrion calcium flux augmentation due to the increase in mitochondrion size and number, which could stimulate calcium-dependent proteases. ${ }^{129}$ However, few studies have discussed the relationship between body fat accumulation and amino acid metabolism in order to verify the possible modifications in amino acid metabolic pathways caused by an elevated fat intake.

\section{The central nervous system "feeding" hypothesis}

One of the hypotheses that can be explained by the reduction in glucose utilization as a result of insulin resistance, as described above, ${ }^{124}$ is to ensure glucose availability to central nervous system cells. In normal individuals, long-term signals of lipid cell metabolism, such as leptin
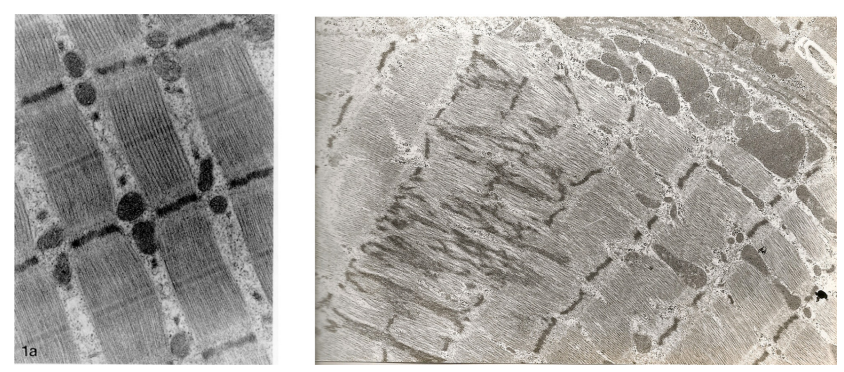

Figure 4 Micrograph of mitochondrial impairment caused by aspartate and asparagine supplementation in a rat model.

Notes: The left panel shows the soleus muscle of the sedentary control group $(15,000 \times)$ and the right panel shows the soleus muscle of the supplemented group (aspartate and asparagine) $(7000 \times) .{ }^{117}$ and insulin levels, are regulated by body fat stores; these hormones modulate central effectors of energy balance by regulating central nervous system responses to shortterm meal-related signals. ${ }^{130}$ In obese individuals, these mechanisms are blunted by either genetic or environmental reasons, for example, increased efferent parasympathetic activity in the endocrine pancreas, mediated by the vagus nerve, was observed early in genetically obese rats (fa/fa) who received arginine infusion, resulting in higher insulin secretion compared to lean animals. ${ }^{131}$ On the other hand, Nogueiras et a ${ }^{132}$ found that obese mice lost the capacity of modulating adipocyte metabolism through glucagon-like peptide 1 system, which is one of the functions controlling fat deposition, enhancing insulin release, and reducing both glucagon levels and gastric emptying via neuroendocrine mechanisms.

In general, obese individuals' diets are characterized by excessive caloric ingestion, mainly due to larger protein and lipid intake and, proportionally, lower carbohydrate ingestion. For this reason, carbohydrate stores may not be available to the tissues in the same intensity as the other two macronutrients, and the increase in insulin levels may be interpreted as an attempt to modulate peripheral hormonal responses to augment glucose uptake for the central nervous system. For instance, daily fluctuations in energy balance (towards a deficit) in premenopausal women seem to be the most influent factor in changing ovarian estrogen exposure and sex hormone-binding 
globulin levels, which correlate with a reduction in insulin level. ${ }^{133}$ Maybe the opposite takes place in obese subjects: increased insulin levels reduce sex hormone-binding globulin levels, ${ }^{134}$ which are correlated to increased abdominal fat and the presence of metabolic alterations in men and women. ${ }^{135}$

\section{Experimental models of obesity}

The study of obesity in humans would probably answer many questions; however, these kinds of studies have several ethical and financial limitations. Experimental studies allow a greater quantity of inquiries and results, and feature more controlled diet and health conditions where the animals can be kept free of pathogens. Although experimental obesity models cannot be compared to human obesity models, they are of great value in the study of biochemical, physiological, and pathological conditions necessary for the accumulation of excessive body fat. In the last 20 years, knowledge about various factors leading to obesity and its metabolic and endocrine consequences has been increasing. Much of this was generated by experimental obesity models. ${ }^{136}$

Many forms of genetically inherited obesity are described in the literature. ${ }^{137}$ Rodents such as Sprague Dawley rats are particularly propitious to obesity caused by high-fat (cafeteria) diets, due to their polygenic heritage. Some authors believe that this is an appropriate and realistic model to study human obesity. ${ }^{138,139}$ However, some alterations found in human obesity do not occur in these genetic animal models, for example, an increase in fat-free mass and some hormonal differences. ${ }^{140}$ Thus, it is clear that the study of obesity in genetically altered animals has several limitations; some models can only be used for evaluation of specific obesity alterations, but are inappropriate for other investigations.

Other than that, due to the fact that a rapid increase in obesity cases worldwide is related to the lack of physical activity ${ }^{141,142}$ and higher food availability and intake, ${ }^{2,142,143}$ many studies have been performed using the so-called "nongene obesity models" which consist of increasing food intake in laboratory animals. ${ }^{144}$ However, in rodents, for example, it is hard to elevate caloric intake spontaneously, even when the diet is flavored.

Obesity development is possible though, even without a caloric intake increment, because a change in nutrient composition or in dietary patterns influences the efficiency of food utilization and, consequently, increases fat storage per consumed calorie. In practical terms, an increase in diet density may result in caloric intake augmentation or a raise in caloric ingestion of a determined macronutrient, resulting in an increase of body fat. High-carbohydrate diets and/or high-fat diets, as well as a cafeteria diet, have also been used to develop obesity in rats.

A cafeteria diet consists of fat-rich foods often found in coffee shops and supermarkets (eg, cookies, salami, cheese, bread) and many experimental studies in rats have used this diet protocol. This technique is aimed at mimicking the food patterns of modern diets, which consist of many cafeteria and fast food meals in experimental conditions, characterizing a high-fat diet named "western diet." ", $, 19,21,34$ In fact, some studies demonstrate an increase in fat intake in animals fed with this kind of food: ${ }^{137}$ however, these studies have limitations. In a pilot study performed in the authors' laboratory, evaluating and controlling the animal intake of different kinds of food was difficult. In the experimental group, food intake was extremely heterogeneous and hard to evaluate, since 1 day after making the food available to the animals in individual cages, it was not possible to separate each meal to calculate both their intake in terms of macronutrients and the type of fat consumed. This aspect has been the object of much controversy, mainly in studies of diet-induced thermogenesis. ${ }^{140,145-147}$

An increase in body fat storage can be attained by augmenting diet fat intake; however it is advisable to avoid a reduction in protein/energy rate in order to avoid the impairment of growth and development of the experimental animals. In practical terms, diets containing $60 \%$ of fat and $30 \%$ of protein initially used butter and eggs; lard and casein have been used more recently in order to reduce the cost of food preparation. This composition also allows the high intake of saturated fatty acids similar to that observed in western diets. The most recent Consumer Expenditure Survey published by the Brazilian Institute of Statistics and Geography found that lipids contributed $27.6 \%, 31.5 \%$ of which consisted of saturated fat, to household food consumption. ${ }^{148}$ Results found by the authors' group indicated a high intake of saturated fatty acids in the diet of obese women: $62.4 \%$ of lipid intake was related to saturated fatty acids (unpublished observations), which corresponds to $17 \%$ of total caloric value. According to the American Heart Association, ${ }^{149}$ fatty acid ingestion should not exceed $7 \%$ of daily total caloric intake. In an attempt to develop experimental models that enable studies of obesity and its consequences, this high saturated fat intake is interesting, since the contribution of this type of fat in the impairment of insulin sensitivity due to obesity has been demonstrated. ${ }^{102}$ This alteration in plasma insulin levels seems to be highly related to other associated 
pathologies, such as hypertension, dyslipidemia, ${ }^{150}$ and atherosclerosis. ${ }^{11}$

\section{Conclusion}

More studies are necessary to elucidate the environmental factors and molecular mechanisms that induce obesity, especially in Brazil, since the low-income population seems to be more vulnerable to this disease and will lead to enormous health cost increases in the future.

The link between amino acid metabolism and insulin resistance, among others, leads to a fertile field for new information on obesity etiology. Experimental models are important in obesity research due to more controlled experimental conditions, although care must be taken to extrapolate this data to human subjects.

It is crucial to stimulate physical activity and dietary pattern change through both education and government strategies worldwide.

\section{Acknowledgments}

The authors are very grateful to Fundação de Amparo à Pesquisa do Estado de São Paulo (FAPESP) for supporting this research (Project FAPESP 96/08618-6).

\section{Disclosure}

The authors report no conflicts of interest in this work.

\section{References}

1. National Center for Health Statistics. Health, United States, 2006. Chartbook on Trends in the Health of Americans. Hyattsville, MD: National Center for Health Statistics; 2006.

2. World Health Organization. Obesity: preventing and managing the global epidemic. Geneva: World Health Organization; 1998. Technical Report Series No. 894.

3. Popkin BM, Doak CM. The obesity epidemic is a worldwide phenomenon. Nutr Rev. 1998;56(4 Pt 1):106-114.

4. Monteiro CA, Mondini L, Souza ALM, Popkin BM. From malnutrition to obesity: the nutritional transition in Brazil. In: Monteiro CA, editor. Old and New Evils Health in Brazil: The Country's Evolution and its Diseases. São Paulo: Hcitec-NUPENS/USP. 1995:247-255. Portuguese.

5. Monteiro CA, Conde WL, Popkin BM. Income-specific trends in obesity in Brazil: 1975-2003. The nutrition transition in Brazil. Am J Public Health. 2007;91(10):1808-1812.

6. Francischi RP, Pereira LO, Freitas CS, et al. Obesity: update in its etiology, morbidity and treatment. Rev Nutr. 2000;13:17-28. Portuguese.

7. Francischi RP, Pereira LO, Lancha AH Jr. Exercise, eating behavior and obesity: a review of the effects on body composition and metabolic parameters. Rev Paul Educ Fis. 2001;15:117-140. Portuguese.

8. Kuczmarski RJ, Flegal KM, Campbell SM, Johnson CL. Increasing prevalence of overweight among US adults. The National Health and Nutrition Examination Surveys, 1960 to 1991. JAMA. 1994;272(3): 205-211.

9. Hedley AA, Ogden CL, Johnson CL, Carroll MD, Curtin LR, Flegal KM. Prevalence of overweight and obesity among US children, adolescents, and adults, 1999-2002. JAMA. 2004;291(23): $2847-2850$.
10. O'Dea K. Westernization and non-insulin-dependent diabetes in Australian Aborigine. Ethn Dis. 1991;1(2):171-187.

11. DeFronzo RA, Ferrannini E. Insulin resistance. A multifaceted syndrome responsible for NIDDM, obesity, hypertension, dyslipidemia, and atherosclerotic cardiovascular disease. Diabetes Care. 1991;14(3): 173-194.

12. McNamara DJ, Howell WH. Epidemiologic data linking diet to hyperlipidemia and arteriosclerosis. Semin Liver Dis. 1992;12(4): 347-355.

13. Stunkard AJ, Wadden TA. Psychological aspects of human obesity. In: Björntorp P, Brodoff BN, editors. Obesity. Philadelphia: JB Lippincott Company; 1992:352-360.

14. Björntorp P, Brodoff BN, editors. Obesity. Philadelphia: JB Lippincott Company; 1992.

15. Després JP, Lamarche B. Low-intensity endurance exercise training, plasma lipoproteins and the risk of coronary heart disease. $J$ Intern Med. 1994;236(1):7-22.

16. Zhang WM, Kuchár S, Mozes S. Body fat and RNA content of the VMH cells in rats neonatally treated with monosodium glutamate. Brain Res Bull. 1994;35(4):383-385.

17. Hill JO, Peters JC. Environmental contributions to the obesity epidemic. Science. 1998;280(5368):1371-1374.

18. Jebb SA. The Nutrition Society Medical Lecture. Obesity: from molecules to man. Proc Nutr Soc. 1999;58(1):1-14.

19. World Health Organization. Diet, nutrition and the prevention of chronic diseases. Geneva: World Health Organization; 1990. Technical Report Series No. 797.

20. World Health Organization. Physical status: the use and interpretation of anthropometry. Geneva: World Health Organization; 1995. Technical Report Series No. 854.

21. Rolls BJ, Shide DJ. The influence of dietary fat on food intake and body weight. Nutr Rev. 1992;50(10):283-290.

22. Schulz LO, Schoeller DA. A compilation of total daily energy expenditures and body weights in healthy adults. Am J Clin Nutr. 1994;60(5):676-681.

23. Haapanen N, Miilunpalo S, Pasanen M, Oja P, Vuori I. Association between leisure time physical activity and 10-year body mass change among working-aged men and women. Int J Obes Relat Metab Dis. 1997;21(4):288-296.

24. Grundy SM. Multifactorial causation of obesity: implications for prevention. Am J Clin Nutr. 1998;67(Suppl 3):563S-572S.

25. Melby CL, Commerford SR, Hill JO. Exercise, macronutrient balance, and weight control. In: Lamb DR, Murray R, editors. Perspectives in Exercise Science and Sports Medicine, Volume 11. Exercise, Nutrition, and Weight Control. Carmel, IN: Cooper Publishing Group;1998:1-60.

26. Hill JO, Melanson EL, Wyatt HT. Dietary fat intake and regulation of energy balance: implications for obesity. $J$ Nutr. 2000;130(Suppl 2): 284S-288S.

27. Pereira LO, Francischi RP, Klopfer M, et al. Obesity and its implications: effects of physical activity and nutritional control. Rev Bras Nutr Clin. 1999;14:9-17. Portuguese.

28. Friel S, Chopra M, Satcher D. Unequal weight: equity oriented policy responses to the global obesity epidemic. BMJ. 2007;335(7632): 1241-1243.

29. Freitas CS, Klopfer M, Vieira P, et al. Profile of the obese women attending a physical activity program in School of Physical Education and Sport. Paper presented at: 10th Scientific Initiation Conference of UNESP; Oct 1998; São Paulo, Brazil. Portuguese.

30. Mahan LK, Escott-Stump S. Krause's Food, Nutrition, and Diet Therapy. 9th ed Philadelphia, PA: WB Saunders Co; 1996.

31. Pereira LO, Francischi RP, Klopfer M, et al. Different intensities of physical activities with or without hypocaloric diet: effects on body composition, food consumption and plasmatic profile in obese women [abstract]. Med Sci Sports Exerc. 1998;30(5):238.

32. Pereira LO, Klopfer M, Vieira P, et al. The evaluation of the best strategy to increase muscle mass and improve health in obese women. Proc Nutr Soc. 1999;59:99. 
33. Francischi RP, Oquendo L, Campos PL, Futigami S, Neto SRC, Lancha AH Jr. Physical activity and nutritional control features a treatment of obesity in Brazilian women. Paper presented at the 10th International Conference of Biochemistry of Exercise; July 15-19, 1997; Sydney, Australia.

34. Francischi RP, Klopfer M, Pereira LO, et al. Effect of physical activity intensity and hypocaloric diet upon food intake, body composition and cholesterolemia of obese women. Rev Bras Nutr Clin. 1999;14:1-8. Portuguese.

35. Francischi RP, Santos RC, Vieira P, et al. Effects of exercise on dietary composition, metabolism and body composition of Brazilian obese women. Scand J Nutr. 1999;43(34s):40S.

36. Monteiro CA, Conde WL. The secular trend of obesity according to social strata: northeast and southeast of Brazil, 1975-1989-1997. Arq Bras Endocrinol Metab. 1999;43(3):186-194. Portuguese.

37. Monteiro CA, Conde WL, Popkin BM. The burden of disease from undernutrition and overnutrition in countries undergoing rapid nutrition transition: a view from Brazil. Am J Public Health. 2004;94(3):433-434.

38. Monteiro CA, D'A Benicio MH, Conde WL, Popkin BM. Shifting obesity trends in Brazil. Eur J Clin Nut. 2000;54(4): 342-346.

39. Pereira-Lancha LO, Coelho DF, de Campos-Ferraz PL, Lancha AH Jr. Body fat regulation: is it a result of a simple energy balance or a high fat intake? J Am Coll Nutr. 2010;29(4):343-351.

40. West DB, York B. Dietary fat, genetic predisposition, and obesity: lessons from animal models. Am J Clin Nutr. 1998;67(Suppl 3) 505S-512S.

41. Llado I, Rodriguez-Cuenca S, Pujol E, et al. Gender effects on adrenergic receptor expression and lipolysis in white adipose tissue of rats. Obes Res. 2002;10(4):296-305.

42. Ainslie DA, Proietto J, Fam BC, Thorburn AW. Short-term, high-fat diets lower circulating leptin concentrations in rats. Am J Clin Nutr. 2000;71(2):438-442.

43. Frederich RC, Hamann A, Anderson S, Lollmann B, Lowell BB, Flier JS. Leptin levels reflect body lipid content in mice: evidence for diet-induced resistance to leptin action. Nat Med. 1995;1(12): 1311-1314.

44. Pomplun D, Voigt A, Schulz TJ, Thierbach R, Pfeiffer AF, Ristow M. Reduced expression of mitochondrial frataxin in mice exacerbates diet-induced obesity. Proc Natl Acad Sci U S A. 2007;104(15): 6377-6381.

45. Townsend KL, Lorenzi MM, Widmaier EP. High-fat diet-induced changes in body mass and hypothalamic gene expression in wild-type and leptin-deficient mice. Endocrine. 2008;33(2):176-188.

46. Houseknecht KL, Baile CA, Matteri RL, Spurlock ME. The biology of leptin: a review. J Anim Sci. 1998;76(5):1405-1420.

47. Stanley S, Wynne K, McGowan B, Bloom S. Hormonal regulation of food intake. Physiol Rev. 2005;85(4):1131-1158.

48. Little TJ, Horowitz M, Feinle-Bisset C. Modulation by high-fat diets of gastrointestinal function and hormones associated with the regulation of energy intake: implications for the pathophysiology of obesity. Am J Clin Nutr. 2007;86(3):531-541.

49. How JM, Fam BC, Verberne AJ, Sartor DM. High fat diet is associated with blunted splanchnic sympathoinhibitory responses to gastric leptin and cholecystokinin: implications for circulatory control. Am J Physiol Heart Circ Physiol. 2011;300(3):H961-H967.

50. Swartz TD, Savastano DM, Covasa M. Reduced sensitivity to cholecystokinin in male rats fed a high-fat diet is reversible. $J$ Nutr. 2010;140(9):1698-1703.

51. Batterham RL, Cohen MA, Ellis SM, et al. Inhibition of food intake in obese subjects by peptide YY3-36. N Engl J Med. 2003;349(10): 941-948.

52. Batterham RL, Heffron H, Kapoor S, et al. Critical role for peptide YY in protein-mediated satiation and body-weight regulation. Cell Metab. 2006;4(3):223-233.
53. Ueno H, Yamaguchi H, Mizuta M, Nakazato M. The role of PYY in feeding regulation. Regul Pept. 2008;145(1-3):12-16.

54. Karra E, Chandarana K, Batterham RL. The role of peptide YY in appetite regulation and obesity. J Physiol. 2009;587(Pt 1):19-25.

55. Adams SH, Lei C, Jodka CM, et al. PYY[3-36] administration decreases the respiratory quotient and reduces adiposity in diet-induced obese mice. J Nutr. 2006;136(1):195-201.

56. Boey D, Lin S, Enriquez RF, et al. PYY transgenic mice are protected against diet-induced and genetic obesity. Neuropeptides. 2008;42(1): 19-30.

57. Sloth B, Holst JJ, Flint A, Gregersen NT, Astrup A. Effects of PYY1-36 and PYY3-36 on appetite, energy intake, energy expenditure, glucose and fat metabolism in obese and lean subjects. Am J Physiol Endocrinol Metab. 2007;292(4):E1062-E1068.

58. English PJ, Ghatei MA, Malik IA, Bloom SR, Wilding JP. Food fails to suppress ghrelin levels in obese humans. J Clin Endocrinol Metabol. 2002;87(6):2984.

59. Hooper LE, Foster-Schubert KE, Weigle DS, Sorensen B, Ulrich CM, McTiernan C. Frequent intentional weight loss is associated with higher ghrelin and lower glucose and androgen levels in postmenopausal women. Nutr Res. 2010;30(3):163-170.

60. Cummings DE, Purnell JQ, Frayo RS, Schmidova K, Wisse BE, Weigle DS. A preprandial rise in plasma ghrelin levels suggests a role in meal initiation in humans. Diabetes. 2001;50(8): 1714-1719.

61. Erdmann J, Tahbaz R, Lippl F, Wagenpfeil S, Schusdziarra V. Plasma ghrelin levels during exercise - effects of intensity and duration. Regul Pept. 2007;143(1-3):127-135.

62. Prentice AM. Manipulation of dietary fat and energy density and subsequent effects on substrate flux and food intake. Am J Clin Nutr. 1998;67(Suppl 3):535S-541S.

63. Tagle MA. Nutrition. São Paulo: Artes Médicas; 1981. Portuguese.

64. Pike RL, Brown ML. Nutrition: An Integrated Approach. New York, NY: John Wiley \& Sons; 1967.

65. Miller GD, Hrupka BJ, Gietzen DW, Rogers QR, Stern JS. Rats on a macronutrient self-selection diet eat most meals from a single food cup. Appetite. 1994;23(1):67-78.

66. Romieu I, Willett WC, Stampfer MJ, et al. Energy intake and other determinants of relative weight. Am J Clin Nutr. 1988;47(3): 406-412.

67. Wang H, Storlien LH, Huang XF. Effects of dietary fat types on body fatness, leptin, and ARC leptin receptor, NPY, and AgRP mRNA expression. Am J Physiol Endocrinol Metab. 2002;282(6): E1352-E1359.

68. Matsuo T, Suzuki M. Beef tallow diet decreases lipoprotein lipase activities in brown adipose tissue, heart, and soleus muscle by reducing sympathetic activities in rats. J Nutr Sci Vitaminol (Tokyo). 1994;40(6): $569-581$.

69. Awad AB, Zepp EA. Alteration of rat adipose tissue lipolytic response to norepinephrine by dietary fatty acid manipulation. Biochem Biophysiol Res Commun. 1979;86(1):138-144.

70. Takeuchi H, Matsuo T, Tokuyama K, Shimomura Y, Suzuki M. Dietinduced thermogenesis is lower in rats fed a lard diet than in those fed a high oleic safflower oil diet, a safflower oil diet or a linseed oil diet. J Nutr. 1995;125(4):920-925.

71. Takeuchi H, Matsuo T, Tokuyama K, Suzuki M. Effect of dietary fat type on beta-oxidation of brown adipose tissue and $\mathrm{Na}+$ channel density of brain nerve membrane in rats. J Nutr Sci Vitaminol (Tokyo). 1996; 42(2):161-166.

72. Power GW, Newsholme EA. Dietary fatty acids influence the activity and metabolic control of mitochondrial carnitine palmitoyltransferase I in rat heart and skeletal muscle. $J$ Nutr. 1997;127(11): 2142-2150.

73. Ivkovic-Lazar T, Lepsanovic L, Babic L, Stokic E, Tesic D, MedicStojanoska M. The metabolic X syndrome -4 case reports. Med Pregl. 1992;45(5-6):210-214. Croatian.

74. Hauner H. Abdominal obesity and coronary heart disease. Pathophysiology and clinical significance. Herz. 1995;20(1):47-55. German. 
75. Kim JK, Wi JK, Youn JH. Metabolic impairment precedes insulin resistance in skeletal muscle during high-fat feeding in rats. Diabetes. 1996;45(5):651-658.

76. American Diabetes Association. Report of the expert committee on the diagnosis and classification of diabetes mellitus. Diabetes Care. 1997;20(7):1183-1197.

77. Haus JM, Solomon TP, Marchetti CM, Edmison JM, Gonzalez F, Kirwan JP. Free fatty acid-induced hepatic insulin resistance is attenuated following lifestyle intervention in obese individuals with impaired glucose tolerance. J Clin Endocrinol Metab. 2010;95(1):323-327.

78. Nielsen S, Guo Z, Johnson CM, Hensrud DD, Jensen MD. Splanchnic lipolysis in human obesity. J Clin Invest. 2004;113(11):1582-1588.

79. Lebovitz HE, Banerji MA. Point: visceral adiposity is causally related to insulin resistance. Diabetes Care. 2005;28(9):2322-2325.

80. Weiss EP, Brandauer J, Kulaputana O, et al. FABP2 Ala54Thr genotype is associated with glucoregulatory function and lipid oxidation after a high-fat meal in sedentary nondiabetic men and women. Am J Clin Nutr. 2007;85(1):102-108.

81. Silva MN, Markland D, Minderico CS, et al. A randomized controlled trial to evaluate self-determination theory for exercise adherence and weight control: rationale and intervention description. BMC Public Health. 2008;8:234-246.

82. Manson JE, Skerrett PJ, Greenland P, Vanltallie TB. The escalating pandemics of obesity and sedentary lifestyle. A call to action for clinicians. Arch Intern Med. 2004;164(3):249-258.

83. Laaksonen DE, Lakka HM, Salonen JT, Niskanen LK, Rauramaa R, Lakka TA. Low levels of leisure-time physical activity and cardiorespiratory fitness predict development of the metabolic syndrome. Diabetes Care. 2002;25(9):1612-1618.

84. Golay A, Felber JP, Meyer HU, Curchod B, Maeder E, Jéquier E. Study on lipid metabolism in obesity diabetes. Metabolism. 1984;33(2):111-116.

85. Lancha AH Jr, Poortmans JR, Pereira LO. The effect of 5 days of aspartate and asparagine supplementation on glucose transport activity in rat muscle. Cell Biochem Funct. 2009;27(8):552-557.

86. Felber JP, Golay A. Regulation of nutrient metabolism and energy expenditure. Metabolism. 1995;44(2 Suppl 2):4-9.

87. Segues T, Salvado J, Arola L, Alemany M. Long-term effects of cafeteria diet feeding on young Wistar rats. Biochem Mol Biol Int. 1994;33(2):321-328.

88. Gianotti M, Roca P, Palou A. Body weight and tissue composition in rats made obese by a cafeteria diet. Effect of 24 hours starvation. Horm Metab Res. 1988;20(4):208-212.

89. Sclafani A, Springer D, Kluge L. Effect of quinine adulterated diets on the food intake and body weight of obese and non-obese hypothalamic hyperphagic rats. Physiol Behav. 1976;16(5):631-640.

90. Storlien LH, James DE, Burleigh KM, Chisholm DJ, Kraegen EW. Fat feeding causes widespread in vivo insulin resistance, decreased energy expenditure, and obesity in rats. Am J Physiol. 1986;251(5 Pt 1): E576-E583.

91. Grundleger ML, Thenen SW. Decreased insulin binding, glucose transport, and glucose metabolism in soleus muscle of rats fed a high fat diet. Diabetes. 1982;31(3):232-237.

92. Miller WJ, Sherman WM, Dodd H, Ivy JL. Influence of dietary carbohydrate on skeletal muscle glucose uptake. Am J Clin Nutr. 1985;41(3):526-532.

93. Storlien LH, Baur LA, Kriketos AD, et al. Dietary fats and insulin action. Diabetologia. 1996;39(6):621-631.

94. Rocchini AP, Marker P, Cervenka T. Time course of insulin resistance associated with feeding dogs a high-fat diet. Am J Physiol. 1997; 272(1 Pt 1):E147-E154.

95. Han DH, Hansen PA, Host HH, Holloszy JO. Insulin resistance of muscle glucose transport in rats fed a high-fat diet: a reevaluation. Diabetes. 1997;46(11):1761-1767.

96. Raubenheimer PJ, Nyirenda MJ, Walker BR. A choline-deficient diet exacerbates fatty liver but attenuates insulin resistance and glucose intolerance in mice fed a high-fat diet. Diabetes. 2006;55(7): 2015-2020.
97. Nascimento EB, Fodor M, van der Zon GC, et al. Insulin-mediated phosphorylation of the proline-rich Akt substrate PRAS40 is impaired in insulin target tissues of high-fat diet-fed rats. Diabetes. 2006; 55(12):3221-3228.

98. Wilkes JJ, Bonen A, Bell RC. A modified high-fat diet induces insulin resistance in rat skeletal muscle but not adipocytes. Am J Physiol. 1998;275(4 Pt 1):E679-E686.

99. Oakes ND, Cooney GJ, Camilleri S, Chisholm DJ, Kraegen EW. Mechanisms of liver and muscle insulin resistance induced by chronic high-fat feeding. Diabetes. 1997;46(11):1768-1774.

100. Kraegen EW, Clark PW, Jenkins AB, Daley EA, Chisholm DJ, Storlien LH. Development of muscle insulin resistance after liver insulin resistance in high-fat-fed rats. Diabetes. 1991;40(11): 1397-1403.

101. Stein DT, Stevenson BE, Chester MW, et al. The insulinotropic potency of fatty acids is influenced profoundly by their chain length and degree of saturation. J Clin Invest. 1997;100(2):398-403.

102. Hunnicutt JW, Hardy RW, Williford J, McDonald JM. Saturated fatty acid-induced insulin resistance in rat adipocytes. Diabetes. 1994; 43(4):540-545.

103. Tebbey PW, McGowan KM, Stephens JM, Buttke TM, Pekala PH. Arachidonic acid down-regulates the insulin-dependent glucose transporter gene (GLUT4) in 3T3-L1 adipocytes by inhibiting transcription and enhancing mRNA turnover. J Biol Chem. 1994;269(1): 639-644.

104. Duplus E, Glorian M, Forest C. Fatty acid regulation of gene transcription. J Biol Chem. 2000;275(40):30749-30752.

105. Sparks LM, Xie H, Koza RA, et al. A high-fat diet coordinately downregulates genes required for mitochondrial oxidative phosphorylation in skeletal muscle. Diabetes. 2005;54(7):1926-1933.

106. Tzatsos A, Krandor V. Nutrients suppress phosphatidylinositol 3-kinase/Akt signaling via raptor-dependent mTOR-mediated insulin receptor substrate 1 phosphorylation. Mol Cell Biol. 2006;26(1):63-76

107. Reynolds TH 4th, Cinquino N, Anthony M, Phelps CB, Berk EZ. Insulin resistance without elevated mammalian target of rapamycin complex 1 activity in muscles of mice fed a high fat diet. JApp Physiol. 2009; 107:1479-1485.

108. Lee IS, Shin G, Choue R. Shifts in diet from high fat to high carbohydrate improved levels of adipokines and pro-inflammatory cytokines in mice fed a high-fat diet. Endocr J. 2010;57(1): 39-50.

109. Yu R, Kim CS, Kwon BS, Kawada T. Mesenteric adipose tissue-derived monocyte chemoattractant protein-1 plays a crucial role in adipose tissue macrophage migration and activation in obese mice. Obesity (Silver Spring). 2006;14(8):1353-1362.

110. Saltiel AR. You are what you secrete. Nat Med. 2001;7(8):887-888.

111. Jove M, Planavila A, Sanchez RM, Merlos M, Laguna JC, VazquezCarrera M. Palmitate induces tumor necrosis factor-alpha expression in $\mathrm{C} 2 \mathrm{C} 12$ skeletal muscle cells by a mechanism involving protein kinase $\mathrm{C}$ and nuclear factor-kappaB activation. Endocrinology. 2006;147(1): $552-561$.

112. Borst SE, Lee Y, Conover CF, Shek EW, Bagby GJ. Neutralization of tumor necrosis factor-alpha reverses insulin resistance in skeletal muscle but not adipose tissue. Am J Physiol Endocrinol Metab. 2004; 287(5):E934-E938.

113. Coelho DF, Gualano B, Artioli GG, et al. Exercise training attenuates lipectomy-induced impaired glucose tolerance in rats. Endocr Regul. 2009;43(3):107-116.

114. Zierath JR, Houseknecht KL, Gnudi L, Kahn BB. High-fat feeding impairs insulin-stimulated GLUT-4 recruitment via an early insulinsignaling defect. Diabetes. 1997;46(2):215-223.

115. Pereira LO, Lancha AH Jr. Effect of insulin and contraction up on glucose transport in skeletal muscle. Prog Biophys Mol Biol. 2004; 84(1):1-27.

116. Lancha AH Jr. Physical activity, amino acids supplementation and peripheral insulin resistance. Rev Paul Educ Fis. 1996;10:68-75. Portuguese. 
117. Lancha AH Jr. Effect of amino acids supplementation (aspartate and asparagine) upon glucose transport in rat skeletal muscle [PhD thesis]. Sao Paulo: University of Sao Paulo; 1997. Portuguese.

118. Zierath JR. In vitro studies of human skeletal muscle: hormonal and metabolic regulation of glucose transport. Acta Physiol Scand Suppl. 1995;626:1-96.

119. Lichtenstein AH, Kennedy E, Barrier P, et al. Dietary fat consumption and health. Nutr Rev. 1998;56(5):S3-S28.

120. Ryu MH, Sohn HS, Heo YR, Moustaid-Moussa N, Cha YS. Differential regulation of hepatic gene expression by starvation versus refeeding following a high-sucrose or high-fat diet. Nutrition. 2005;21(4):543-552.

121. Liu HY, Zheng G, Zhu H, Woldegiorgis G. Hormonal and nutritional regulation of muscle carnitine palmitoyltransferase I gene expression in vivo. Arch Biochem Biophys. 2007;465(2):437-442.

122. Koves TR, Ussher JR, Noland RC, et al. Mitochondrial overload and incomplete fatty acid oxidation contribute to skeletal muscle insulin resistance. Cell Metab. 2008;7(1):45-56.

123. Bruce CR, Hoy AJ, Turner N, et al. Overexpression of carnitine palmitoyltransferase- 1 in skeletal muscle is sufficient to enhance fatty acid oxidation and improve high-fat diet-induced insulin resistance. Diabetes. 2009;58(3):550-558.

124. Newsholme EA, Leech AR. Biochemistry for the Medical Sciences. New York, NY: John Wiley \& Sons; 1988.

125. Marshall S, Garvey WT, Traxinger RR. New insights into the metabolic regulation of insulin action and insulin resistance: role of glucose and amino acids. FASEB J. 1991;5(15):3031-3036.

126. Traxinger RR, Marshall SL. Coordinated regulation of glutamine: fructose-6-phosphate amidotransferase activity by insulin, glucose, and glutamine. Role of hexosamine biosynthesis in enzyme regulation. J Biol Chem. 1991;266(16):10148-10154.

127. Lancha AH Jr, Santos MF, Palanch AC, Curi R. Supplementation of aspartate, asparagine and carnitine in the diet causes marked changes in the ultrastructure of soleus muscle. J Submicrosc Cytol Pathol. 1997;29(3):405-408.

128. Rennie MJ, Edwards RH, Krywawych S, et al. Effect of exercise on protein turnover in man. Clin Sci (Lond). 1981;61(5):627-639.

129. Suzuki K, Ohno S. Calcium activated neutral protease - structurefunction relationship and functional implications. Cell Struct Funct. 1990;15(1):1-6.

130. Schwartz MW, Baskin DG, Kaiyala KJ, Woods SC. Model for the regulation of energy balance and adiposity by the central nervous system. Am J Clin Nutr. 1999;69(4):584-596.

131. Rohner-Jeanrenaud F, Jeanrenaud B. Involvement of the cholinergic system in insulin and glucagon oversecretion of genetic preobesity. Endocrinology. 1985;116(2):830-834.

132. Nogueiras R, Perez-Tilve D, Veyrat-Durebex C, et al. Direct control of peripheral lipid deposition by CNS GLP-1 receptor signaling is mediated by the sympathetic nervous system and blunted in diet-induced obesity. J Neurosci. 2009;29(18):5916-5925.

133. Williams NI, Reed JL, Leidy HJ, Legro RS, De Souza MJ. Estrogen and progesterone exposure is reduced in response to energy deficiency in women aged 25-40 years. Hum Reprod. 2010;25(9): 2328-2339.
134. Tymchuk CN, Tessler SB, Barnard RJ. Changes in sex hormonebinding globulin, insulin, and serum lipids in postmenopausal women on a low-fat, high-fiber diet combined with exercise. Nutr Cancer. 2000;38(2):158-162.

135. Hajamor S, Despres JP, Couillard C, et al. Relationship between sex hormone-binding globulin levels and features of the metabolic syndrome. Metabolism. 2003;52(6):724-730.

136. Sclafani A, Springer D. Dietary obesity in adult rats: similarities to hypothalamic and human obesity syndromes. Physiol Behav. 1976; 17(3):461-471.

137. Pereira LO, Francischi RP, Lancha AH Jr. Obesity: nutritional habits, sedentary lifestyle and insulin resistance. Arq Bras Endocrinol Metab. 2003;47:117-127. Portuguese.

138. Festing MFW. The inheritance of obesity in animal models of obesity. In: Festing MFW, editor. Animal Models of Obesity. London: Oxford University Press; 1979:15-37.

139. York DA. Genetic models of animal obesity. In: Björntorp P, Brodoff BN, editors. Obesity. Philadelphia, PA: JB Lippincott Company; 1992:233-240.

140. James WPT, Dauncey MJ, Jung RT, Shetty PS, Trayhurn P. Comparisons of genetic models of obesity in animals with obesity in man. In: Festing MFW, editor. Animal Models of Obesity. London: Oxford University Press; 1979:221-235.

141. Dengel DR, Hagberg JM, Pratley RE, Rogus EM, Goldberg AP. Improvements in blood pressure, glucose metabolism, and lipoprotein lipids after aerobic exercise plus weight loss in obese, hypertensive middle-aged men. Metabolism. 1998;47(9):1075-1082.

142. Seidell JC. Obesity insulin resistance and diabetes - a worldwide epidemic. Br J Nutr. 2000;83 Suppl 1:S5-S8.

143. Keys A, Aravanis C, Van Buchem F, et al. The diet and all-causes death rate in the Seven Countries Study. Lancet. 1981;2(8237):58-61.

144. Sclafani A. Dietary obesity models. In: Björntorp P, Brodoff BN, editors. Obesity. Philadelphia, PA: JB Lippincott Company; 1992: 241-248.

145. Moore BJ. The cafeteria diet - an inappropriate tool for studies of thermogenesis. J Nutr. 1987;117(2):227-231.

146. Rothwell NJ, Stock MJ. The cafeteria diet as a tool for studies of thermogenesis. J Nutr. 1988;118(8):925-928.

147. Argilles JM. The rise and fall of the cafeteria diet: some observations. J Nutr. 1988;118(12):1593-1594.

148. Brazilian Institute of Geography and Statistics (IBGE). Consumer expenditure survey 2002-2003. Analysis of the household availability of food and nutritional status in Brazil. Rio de Janeiro: Brazilian Institute of Geography and Statistics; 2004.

149. American Heart Association. Fats and oils: AHA recommendation [web page on the Internet]. Dallas, TX: American Heart Association; 2012 Available from: http://www.heart.org/HEARTORG/GettingHealthy/ FatsAndOils/Fats 101/Fats-and-Oils-AHA-Recommendation UCM_316375_Article.jsp. Accessed February 17, 2011.

150. Haffner SM, Valdez RA, Hazuda HP, Mitchell BD, Morales PA, Stern MP. Prospective analysis of the insulin-resistance syndrome (syndrome X). Diabetes. 1992;41(6):715-722.

Diabetes, Metabolic Syndrome and Obesity: Targets and Therapy

\section{Publish your work in this journal}

Diabetes, Metabolic Syndrome and Obesity: Targets and Therapy is an international, peer-reviewed open-access journal committed to the rapid publication of the latest laboratory and clinical findings in the fields of diabetes, metabolic syndrome and obesity research Original research, review, case reports, hypothesis formation, expert opinion and commentaries are all considered for publication. The manuscript management system is completely online and includes a very quick and fair peer-review system, which is all easy to use. Visit http://www.dovepress.com/testimonials.php to read real quotes from published authors. 